\title{
DECREASING OF MOVABLE MASSES IN VALVE TIMING USING ROLLER TAPPET
}

\author{
Bogdan Warda, Krzysztof Siczek \\ Technical University of Lodz \\ Department of Vehicles and Fundamentals of Machine Design \\ Zeromskiego Street 116, 90-924 Lodz, Poland \\ tel.: +4842 6312251, +4842 6312250, fax: +48426312252 \\ e-mail:bogdan.warda@p.lodz.pl,ks670907@p.lodz.pl
}

\begin{abstract}
The method for reduction of valve timing movable masses, by the use of composite cams for camshaft, which mate with roller tappet, is presented. It has been carried out an analysis of stresses under the surface of the cam using the methodology and computer programs allowing the synthesis and analysis of the cam mechanism, and to estimate the fatigue life, as well as using the finite element method. Mating roller tappets with a light camshaft, forged from TiAl alloy, can be done if the camshaft has steel caps set under the pressure on the surfaces their cams. The problem, however, is the formation of high stress in the Bielaiev point, when a roller tappet mates with segment cam. Because of the certainty for the cap fixing, it is assumed that the depth for the Bielaiev point should not exceed half the thickness of the cap. The stress analysis shows, that exceeding of the material yield strength is controlled by the interference value between the cam and its cap and by the apex radius of the cam. Effect of contact stress is at least an order of magnitude smaller. The maximum depth of the Bielaiev point does not exceed 0.09 mm, which is about half the thickness of the proposed cap. There is a need not for too small radii between the cam and the apical cap. Optimal selection of proper geometry of the cam will be easier after a proper modification of the program used for the synthesis and analysis of the cam mechanism, such that it is possible to ask any operational surface of the cam profile.
\end{abstract}

Keywords: valve timing, lightweight camshaft, roller tappet

\section{Introduction}

In all internal combustion engines there is valve timing allowing gas exchange, whose aim is to remove gas from the combustion chamber and provide fresh charge for the next cycle. Quite commonly used in large engines the timing mechanism is of OHV type [1].

In the OHV timing, valves are driven from the camshaft, mounted in the cylinder block, through the tappets, pushrods, and rocker arms. An example of such timing system is shown in Fig. 1 [2]. The disadvantage of this valvetrain is a greater inertia, due to the large number of parts, making it difficult to accurate control valve timing at high engine rpm.

The reduction of wear and resistance of motion in that timing is achieved primarily by reducing the mass of moving parts, including valves, springs, tappets.

The four-stroke internal combustion engines timing is carried out using steel poppet valves 1 . In order to reduce their weight they are made of TiAl alloys or as ceramic - of Si3N4.

The valve operation is caused by applying pressure to the valve stem by rocker arm 3 . The rocker arm can be forged steel or made of cast iron. In order to reduce its weight thin wall design is used or less frequently, one forged from TiAl alloys. A limitation of the latter may be too low stiffness. Rocker arm, rotationally mounted on the axis 4, is driven by the tappet 6 and its push rod 5 .

The pushrod 5 is usually made of steel, but can also be of TiAl alloy - but then has a lower resistance to buckling.

The tappet 6 is driven by a rotating cam of the camshaft. It can be forged from steel or TiAl alloy. A limitation of the latter is a need for a hard face of the tappet. 


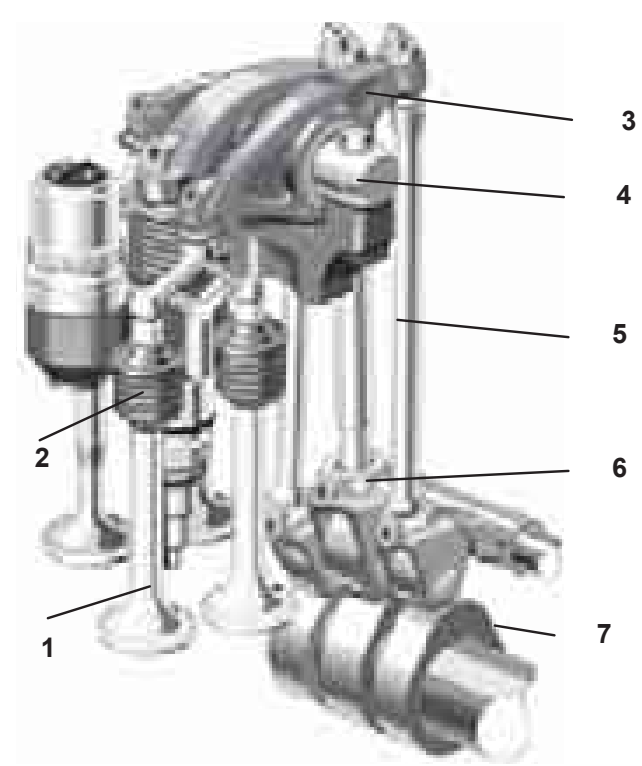

Fig. 1. Valve timing mechanism for 12-liter Scania Diesel engine [2]; 1 -valve, 2 - spring, 3 - valve rocker, 4 - rocker shaft, 5 - tapped rod, 6 - tappet, 7 - camshaft

The valve spring 2 keeps the valve closed tightly into its seat insert until the start of valve opening by the rocker arm 3. When the rocker arm pushes the valve stem and opens the valve 1 , the valve spring 2 is compressed during that time. Such spring pushes the valve 1 to the surface of the rocker arm 3, so that contact is ensured throughout the movement of the valve. The spring 2 is usually made of steel, but can be of TiAl alloy - but such spring has a lower stiffness.

Another possibility to reduce the moving masses in the timing is to reduce the weight of the camshaft 7. The camshaft can be forged from TiAl alloy, but the surfaces of the cams have to be especially hardened. One solution to this problem may be tight joints, the surfaces of titanium cams camshaft with special steel caps.

The aim of this article is the analysis of stresses induced by the tight joint the cap with the cam and by the contact pressure between the cam and roller tappet.

\section{Roller tappets}

Roller tappets are used in heavy-duty engines of large between recovery runs, not exceeding 2000 rpm. Examples include Scania D11, D12 and D16 [3]. Such roller tappets have great masses, and the cost of their implementation is relatively high. The roller tappets carries heavy loading. On its pin, there is a rotating roller, which surface mates with the cam surface. The advantage of the roller tappet is its durability resulting from uniform wear of the rollers on its periphery. The advantages of this tappet are also a small resistance movement and the ability to carry large forces. Fig. 2 shows an exemplary design of the roller tappet. Required maintaining the roller in the symmetry plane of the cam is provided by leading notches, visible in cross section B-B.

Most tappets are made of cast iron C (3-4)\%, Si (1.8-2.5)\%, Mn (0.5-1)\%, Cr (0.15-0.35)\%, $\mathrm{P}$ (up to 0.4$) \%, \mathrm{~S}(<0.1) \%$. The steel with carbon content up to $0.2 \%$ can be sometimes used. For extremely heavy-duty engines, the tappets can be made of $12 \mathrm{HN}$ steel.

Faces for tappets made of cast iron are hardened by accelerated cooling, which ensures formation of the hard cementite structure. Increasing the intensity of cooling is achieved by placing the suitable metal plate in the casting mold.

In the case of forged steel tappets, their faces are hardened by carburizing and induction hardening the surface. In the steel tappets, it is sometimes poured the layer of cast iron, cooled after pouring in a stream of water to form the cementite structure.

Tappet faces are usually grounded in the flat manner. 

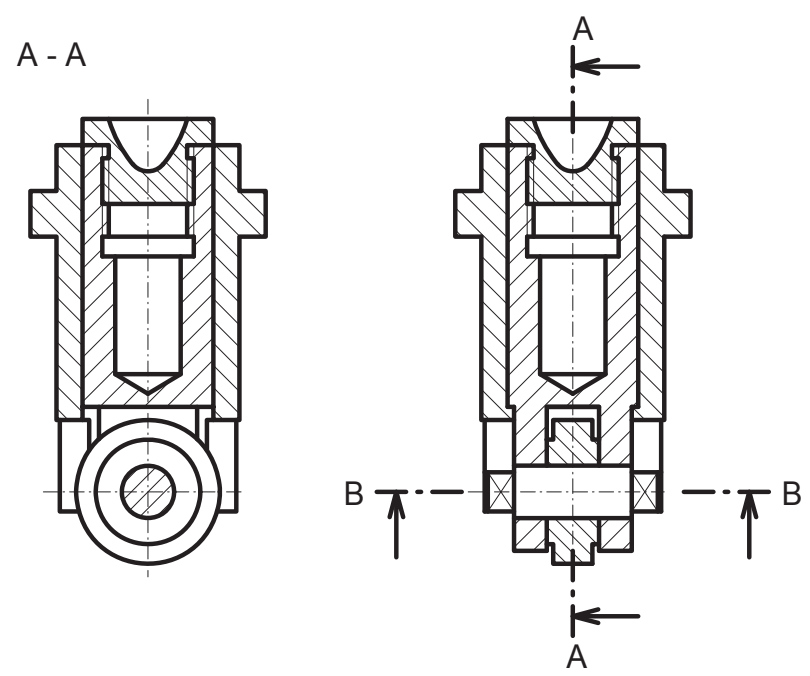

B - B

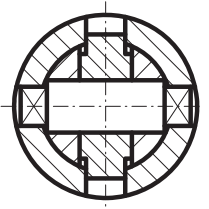

Fig. 2. Roller tappet

Tappets mate with their guides. If the cylinder block is made of cast iron, the tappets are placed directly into the holes of the block, made of $\mathrm{H7}$, with a roughness parameter Ra below $0.8 \mu \mathrm{m}$. For blocks made of light alloy, are used valve guides made of bronze or of cast iron GJL250. The guide wall thickness does not exceed $2-4 \mathrm{~mm}$, depending on the diameter of the tappet. Such guides are embedded with $\mathrm{H} 7 / \mathrm{n} 6$ interference fit, while the cooperating surfaces of the tappets and guides are fitting by $\mathrm{H} 7 / \mathrm{f} 6$ or $\mathrm{H} 7 / \mathrm{g} 7$.

Their contact zone is lubricated with oil delivered mostly in the form of oil mist from the engine lubrication system [4].

\section{Differences between flat and roller tappets}

Manufacturers and designers of racing cars have commonly used a camshaft lobe systems mating with flat tappets. However, they tend to prefer camshafts of cams mating with roller tappets (if the rules allow their use), since the cam, mating with roller tappet has a distinct advantage over the solution that uses a flat tappet.

It is well known that the sliding friction forces are greater than the forces of rolling resistance. Therefore, camshaft mating with roller tappets engages less power to rotate and tends to wear not so quickly. An added benefit is that roller tappets do not require replacement when changing camshaft. When using stationary roller lifters (e.g., P/N 72400LUN), camshaft can be replaced without removing the intake manifold. If the cam profile allows for greater angle-cross section, this allows potentially obtaining more power. Roller profile can be more "aggressive" and provide more acceleration than for flat tappet profile [5] (Fig. 3).

Flat tappet profiles can be shaped to a point where the tappet 'sticks' into the profile. Profile roller tappets are not limited too much by this phenomenon, even making possible to use inverted (concave) radius of the profile [5].

This improves engine performance in two ways: more tappet lift can be achieved without additional time, which is normally required to achieve the higher flat tappet (added) lift, which makes the lift curve more acute; also lift curve can be widened without increasing lift. Of course, both of these benefits can be combined to create a profile that can easily exceed the cam profiles mating with flat tappets.

Timing systems using camshafts mating with roller tappets, however, are much more expensive than those in which the camshafts mating with flat tappets. Much of the additional cost relates specifically to the tappets. However, roller tappets can be used again, unlike the flat tappets. If the motors are frequently galling, the rollers can be used repeatedly, unless they are damaged or show signs of wear. Roller tappets are used in heavy-duty engines of large between recovery runs, not exceeding. 


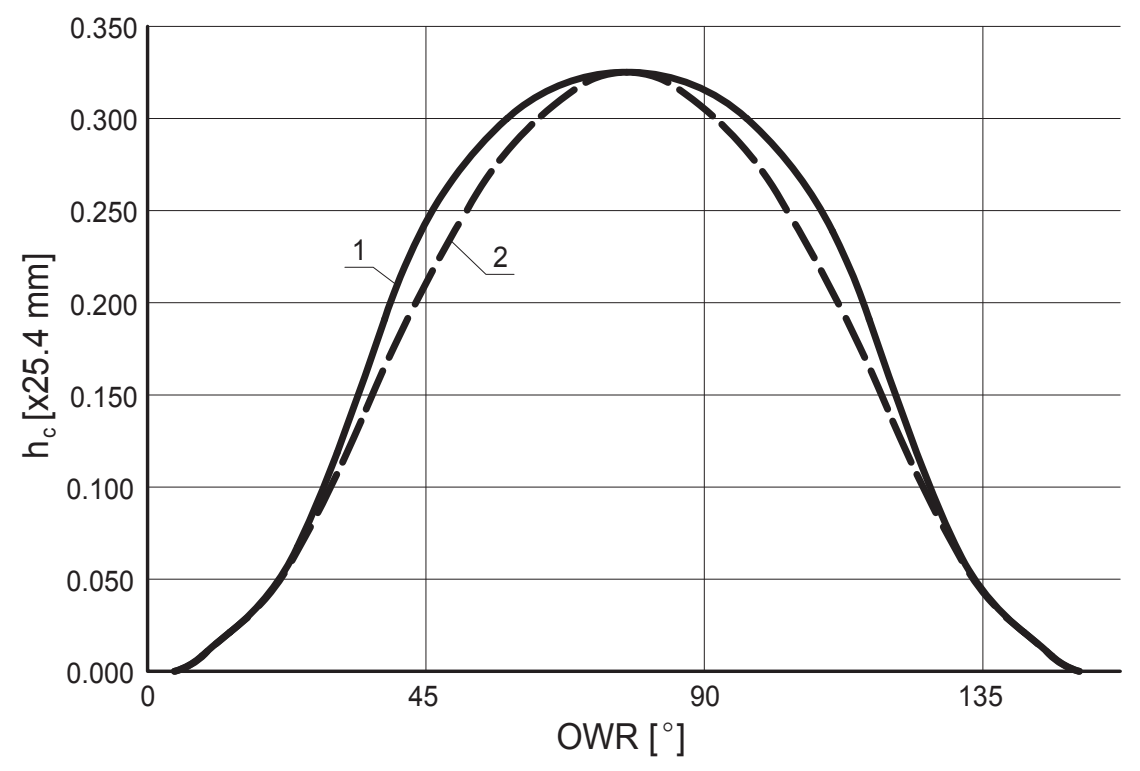

Fig. 3. Comparison between the lift of roller tappet (1) and flat tappet (2) [5]

\section{Adjustable roller tappets}

For many modern engines, there is possibility for disconnection of individual cylinders or valves, to reduce fuel consumption. In this way, depending on engine load, it is possible to optimise their thermodynamic efficiency.

Switchable roller tappets allow switching between full and zero lift (disconnect the valve or cylinder) engines with the camshaft placed at the bottom.

Switchable roller tappet [6] (Fig. 4) consists of two placed one inside the other tappets, so called, the internal tappet 5 and the outer tappet 6 . In the outer tappet 6 , there is the roller 2 mounted rotationally on the pin and mating with the cam. The outer tappet 6 is guided in the cylinder head between the camshaft and pushrod. Inside the internal tappet 5, there is piston 1, which upper face mates with the push rod, and the bottom face mates with the ball valve. The internal tappet 5 is tight with a Lost-Motion-Spring system 7 to the abutment surface in the outer tappet 6 . Both parts of the body can be linked together using a coupling mechanism consisted of locking piston 4, return spring 3. The full lift in the locked condition is transmitted from the cam, through the tappet assembly to the valve. In the unlocked mode, the engine valve is closed, and the cam lobe lift is consumed by the displacement difference between the inner and outer tappets. In comparison to the standard valve timing, the following modifications have been made:

- a switch valve has been included into the engine oil system,

- the protection against rotation the roller tappet relative to its guide has been provided,

- completing ECU with the implementation of the control for the switch valve.

\section{Model of mating the roller of tappet with a hard cap joined tightly with the cam}

As it has been already mentioned, one of the possible reduction of moving masses is to use the timing camshaft forged from TiAl alloy. However, the high requirements in terms of surface hardness for cams, under high pressure and wear, exclude practically the use of homogeneous material throughout the cam volume. You can use cams with hardened surface layer, for example, by plasma nitriding, but this may not be sufficient, given the small thickness of the nitride layer.

Another solution might be tight joints of the steel caps with the cam surfaces of the camshaft. The problem is the formation of high stress in the Bielaiev point, when such a roller tappet mates with such segment cam. Because of the certainty for the cap fixing, it is assumed that the depth for 

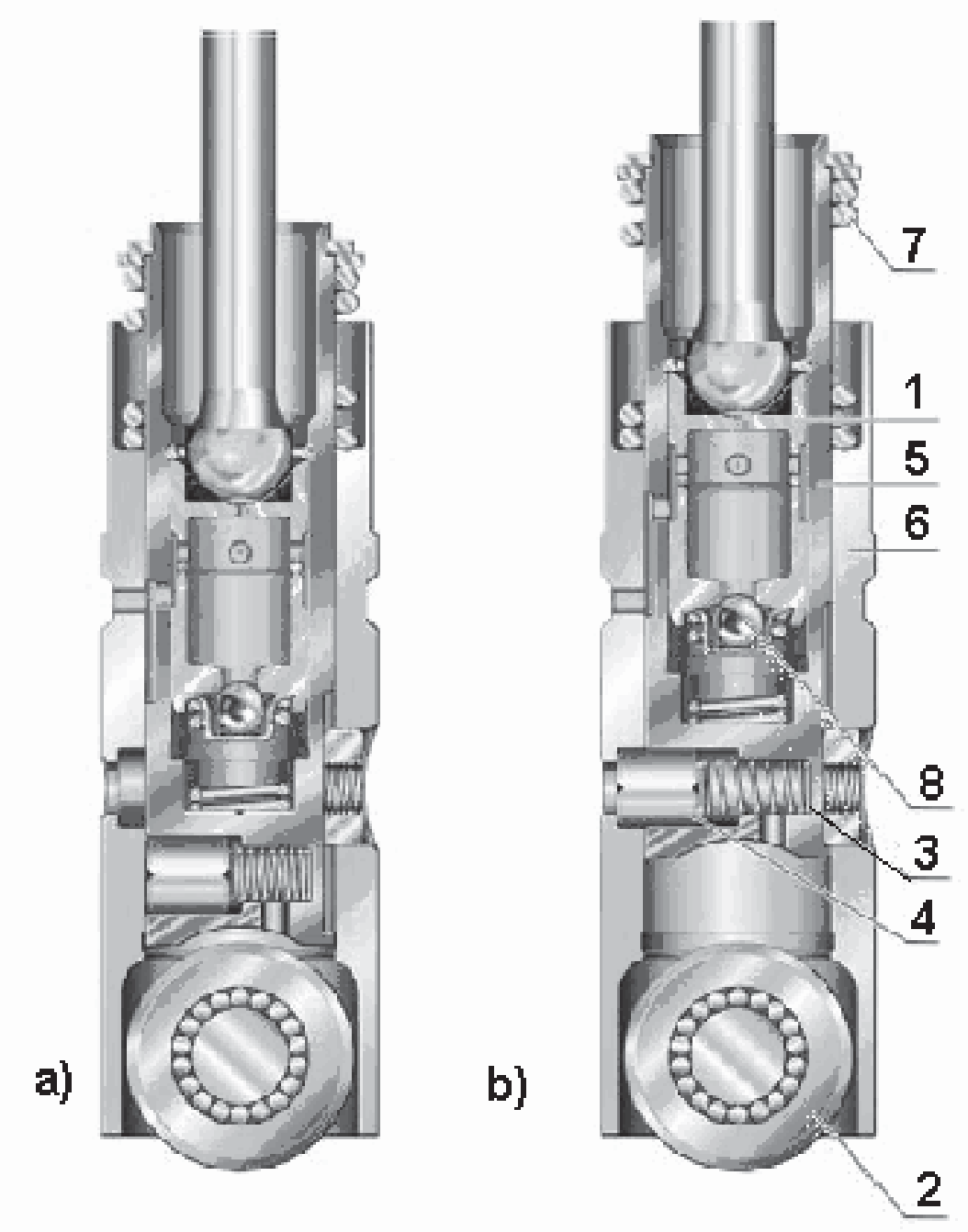

Fig. 4. Adjustable tappet roller; a) unlocked (zero lift), b) locked (full lift);1 - piston, 2-cam roller, 3 - return spring, 4 locking piston, 5 - internal plunger, 6 - outer plunger, 7 - support spring (,,Lost-motion“- spring), 8 - ball valve

the Bielaiev point should not exceed half the thickness of the cap. In addition, stresses superposed of those occurring in Bielaiev point and of caused interference fit, should not exceed the yield strength for cam and cap materials.

For the analysis it has been assumed a radius of the cam base $R_{b}=16 \mathrm{~mm}$, tip radius $R_{w}=3 \mathrm{~mm}$ and a cam lobe lift $\Psi=6 \mathrm{~mm}$. The width of the cam has been equal $l_{k}=7 \mathrm{~mm}$. The cam made of an alloy Ti6A14V and a steel cap of the thickness equal $2 \mathrm{~mm}$, has been of the same width. Interference fit has been equal $0.2 \mathrm{~mm}$. The cam mates with a roll made of the same valve steel with a radius $R_{f}=10 \mathrm{~mm}$ and $6 \mathrm{~mm}$. A higher value corresponds to the tappet rollers used in the timing of large slow-speed diesel engine. The smaller value corresponds to the rollers used in adjustable roller tapped.

A preliminary analysis of the stresses in the material of cam during its mating with roller tappet performed using computer programs called KRZYWKA1 and KRZYWKA2 [7-9]. The first one is used for the synthesis and analysis of the cam mechanism with a linear roller tappet, the second one is used to predict the fatigue life of the cam mechanism, and allows determination of pressure distribution in contact zone the tappet roller with the cam $p$ and the corresponding substitute maximum subsurface stress $\sigma$, defined on the basis of the von Misses hypothesis, and the depth of their occurrence $Z$, according to the position of the Bielaiev point (Fig. 5). 


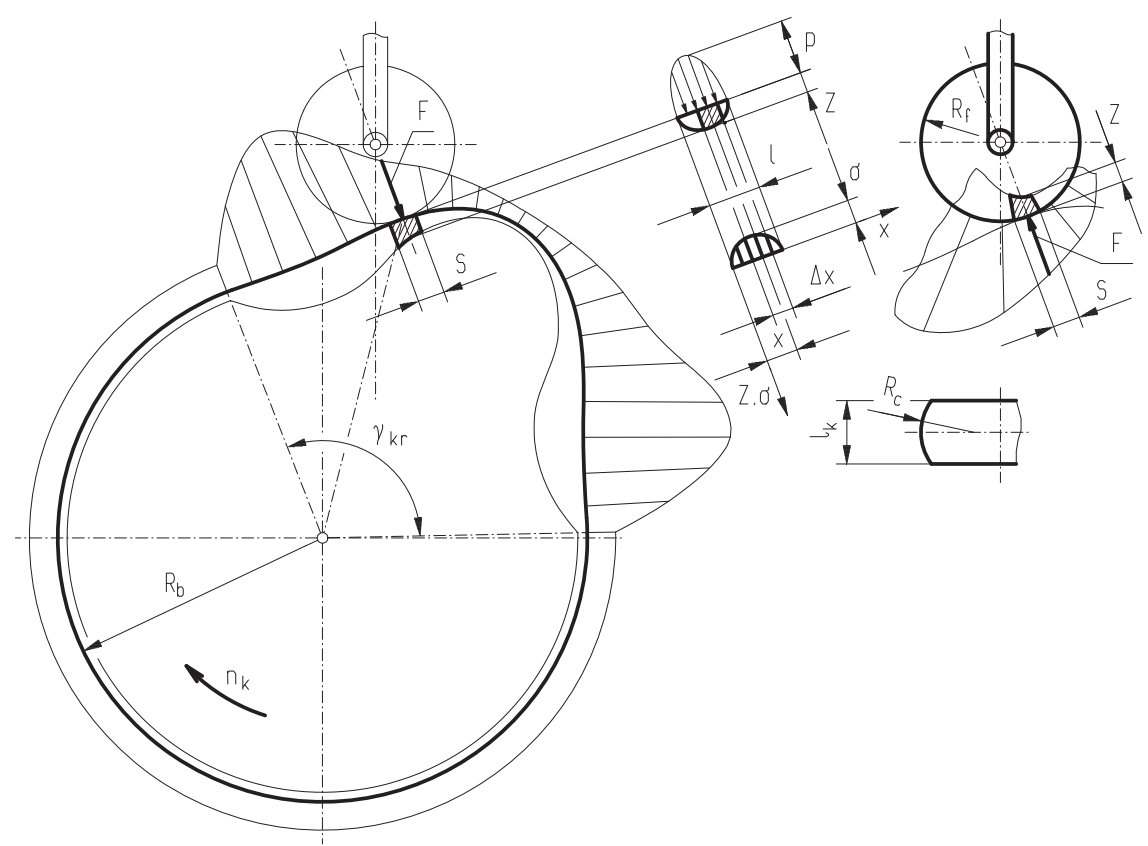

Fig. 5. Modelling of the area under subsurface stresses in a cam mechanism

Table 1 shows the basic parameters of the cam mechanism analysed. It should be noted that the program called KRZYWKA1 only allows for the design of the cam with the trigonometric or polynomial shape. Thus, it has not been possible to tip the radius of the cam.

Figure 6 shows the distribution of the maximum pressure $p_{\max }$, the maximum reduced subsurface stress $\sigma_{\max }$ and depth of their occurrence $Z_{\max }$ as a function of coordinate $S$, measured along the circumference of the cam.

Constant values of pressure, subsurface stresses and depth $Z_{\max }$ correspond to the cam duration period. After entering the tappet roller in contact with the mating part of the cam, the pressures and subsurface stresses slightly decrease, which is associated with a reduction in reduced curvature of solids in their contact zone. At the same time, it increases the depth of the position of the Bielaiev point, which is dependent on the width of the contact fields - more for less reduced curvature.

Tab. 1. Main parameters of the cam mechanism

\begin{tabular}{|l|l|l|}
\hline \multicolumn{1}{|c|}{ Parameter } & \multicolumn{1}{c|}{ Case 1 } & \multicolumn{1}{c|}{ Case 2 } \\
\hline Type the cam mechanism & $\begin{array}{l}\text { the outer cam and roller, } \\
\text { outline: trigonometric functions }\end{array}$ & $\begin{array}{l}\text { the outer cam and roller, } \\
\text { outline: trigonometric functions }\end{array}$ \\
\hline Operational angle of the cam & $\gamma_{k r}=150^{\circ}$ & $\gamma_{k r}=150^{\circ}$ \\
\hline The radius of the cam base & $R_{b}=16 \mathrm{~mm}$ & $R_{b}=16 \mathrm{~mm}$ \\
\hline The lift of tappet & $\Psi=6 \mathrm{~mm}$ & $\Psi=6 \mathrm{~mm}$ \\
\hline Distance for tappet line & $R_{a}=0 \mathrm{~mm}$ & $R_{a}=0 \mathrm{~mm}$ \\
\hline Radius of the roller tappet & $R_{f}=10 \mathrm{~mm}$ & $R_{f}=6 \mathrm{~mm}$ \\
\hline The radius of convexity of the roller & $R_{c}=100 \mathrm{~mm}$ & $R_{c}=100 \mathrm{~mm}$ \\
\hline Width of roller tappet & $l_{k}=7 \mathrm{~mm}$ & $l_{k}=7 \mathrm{~mm}$ \\
\hline Cam mass & $m=0.2 \mathrm{~kg}$ & $m=0.2 \mathrm{~kg}$ \\
\hline Cam speed & $n_{k}=1000 \mathrm{rpm}$ & $n_{k}=1000 \mathrm{rpm}$ \\
\hline Tappet spring stiffness & $C_{p}=20000 \mathrm{~N} / \mathrm{mm}$ & $C_{p}=20000 \mathrm{~N} / \mathrm{mm}$ \\
\hline Initial deflection of the spring & $f_{z}=5 \mathrm{~mm}$ & $f_{z}=5 \mathrm{~mm}$ \\
\hline
\end{tabular}




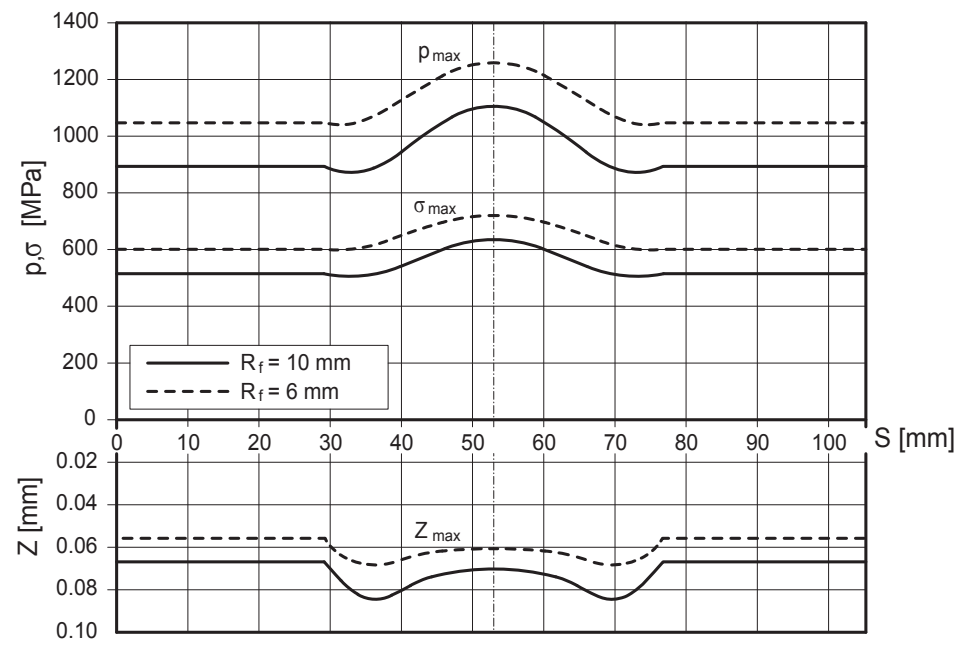

Fig. 6. Contact pressure $p_{\max }$, von Mises stress $\sigma_{\max }$ and Bielaiew point depth $Z_{\max }$

The pressure and subsurface stress reaches the maximum value for the coordinate $S$ corresponding to the vertex of the cam. In this place, the depth of occurrence of maximum subsurface reduced stress is only slightly greater than the depth corresponding to the durability zone of the cam. It should be noted that for both variants of the cam mechanism design, the maximum depth for occurrence of the Bielaiev point does not exceed $0.09 \mathrm{~mm}$, which is about half the thickness of the proposed cap.

Further stress analysis has been performed in the model developed using FEM. It has been used a flat model, which take into account the symmetry plane of the cam to reduce the number of finite elements. The finite elements mesh generated automatically by commercial program ANSYS [10] and the boundary conditions for the three load cases have been shown in Fig. 7.
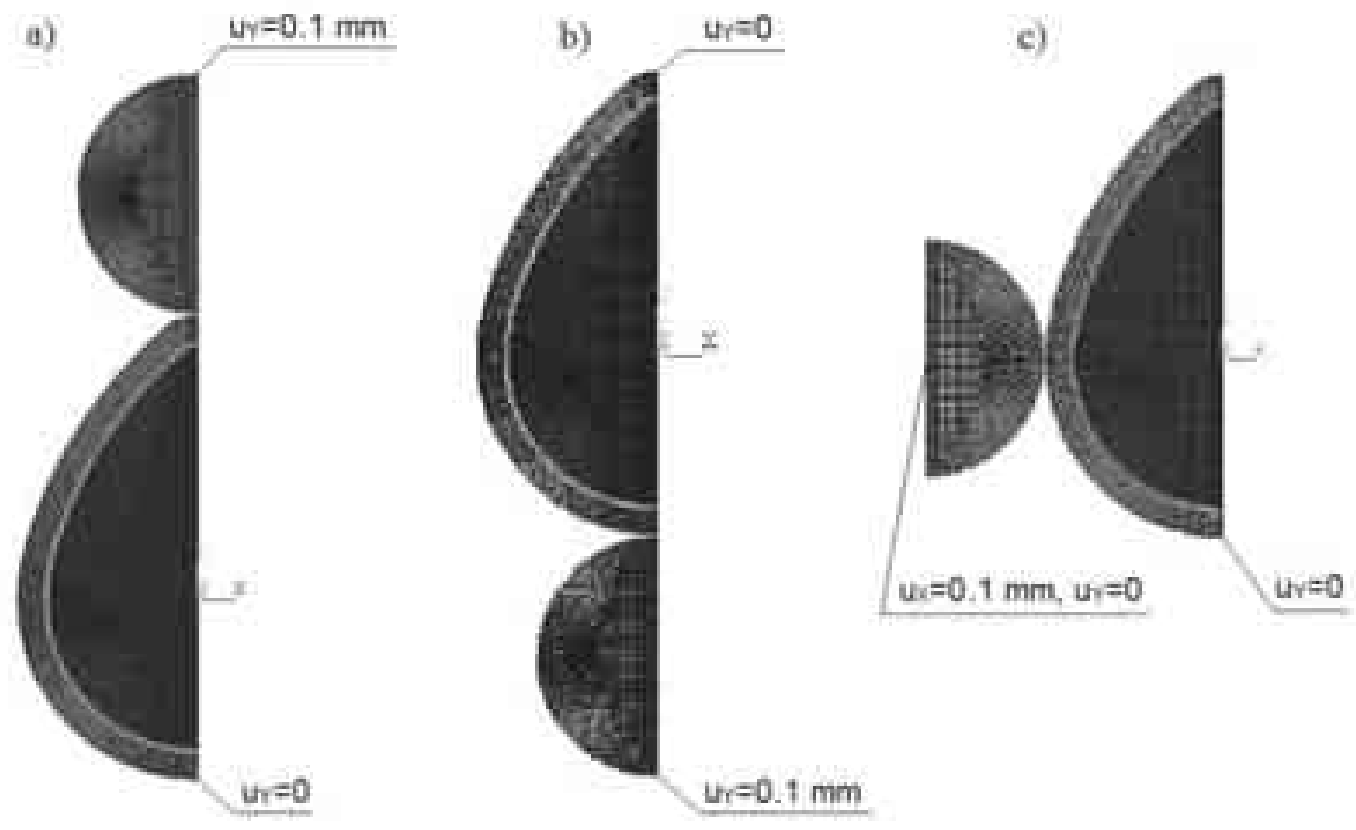

Fig. 7. Finite element mesh and boundary conditions for three angular positions $\alpha$ for roller of tappet in respect to camshaft axis; a) $\alpha=0^{\circ}$, b) $\alpha=180^{\circ}$, c) $\alpha=90^{\circ}$

Calculations have been carried out in two stages. The first calculated the stresses arising from the presence of interference between the cam and its cap. The second stage have included an additional loading of the cam, which has been a result of the forced displacement of $0.1 \mathrm{~mm}$ set into the selected node of the mating roller. It has corresponded to the loading the roller with the force value similar to that used in the analysis of contact stress and occurring in Bielaiev point. 


\section{Results of calculations}

Obtained values of reduced stress have been shown in Fig. 8-10. Fig. 8a-10a represents stress values obtained in the first stage. In Fig. 8b-10b, it has been shown the equivalent stresses obtained in the second stage. It may be noted that in all analysed cases, the material yield strength is exceeded, is determined by the value of interference between the cam and its cap and by the value of apex radius of the cam. Effect of contact stress is at least an order of magnitude smaller. Hence the need for very small apex radii between the cam and its cap. The problem of the interference value remains unsolved, because from the one hand the reduction of interference value between the cam and its cap reduces the risk of exceeding the yield stress in the material of the cam and its cap, but from the other hand too small values of the interference can cause weakness of the cap - cam joint under the influence of the travelling wave of contact stresses. This process may also contribute to insufficient thickness of the cap. Due to the depth of occurrence of Bielaiev point, such thickness should not be less than $0.2 \mathrm{~mm}$. However, the cap cannot be too thick, because it increases the weight of the camshaft. Hence the need to optimise the joint.
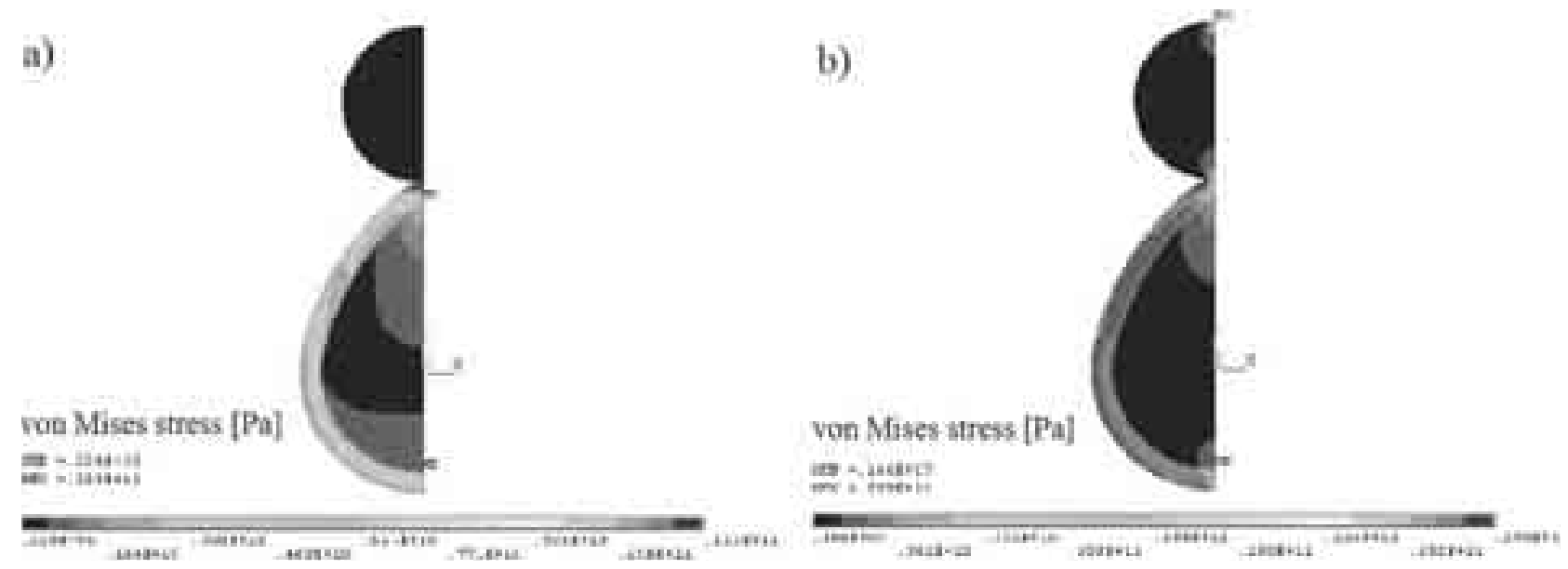

Fig. 8. von Mises stresses for angular position $\alpha=0^{\circ}$ for roller of tappet in respect to camshaft axis; a) the first load case, b) the second load case

a)

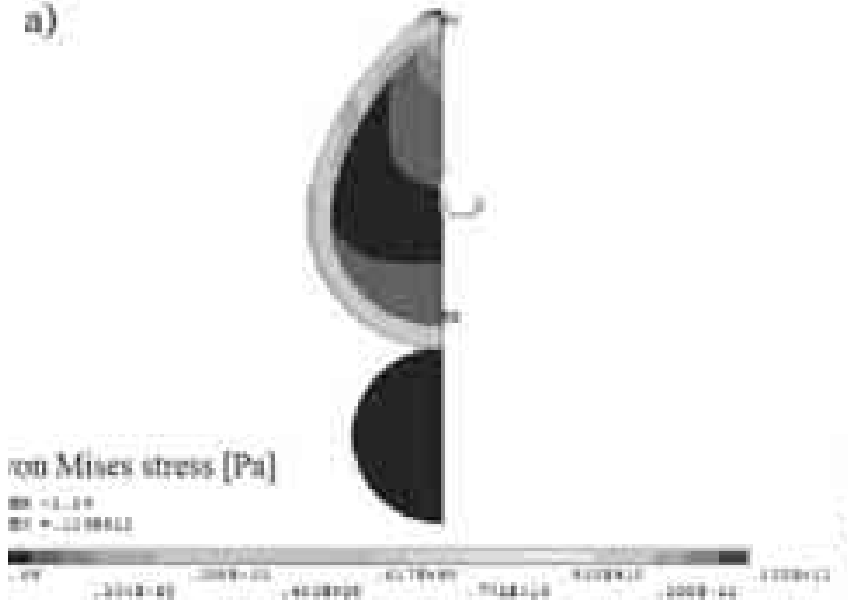

b)

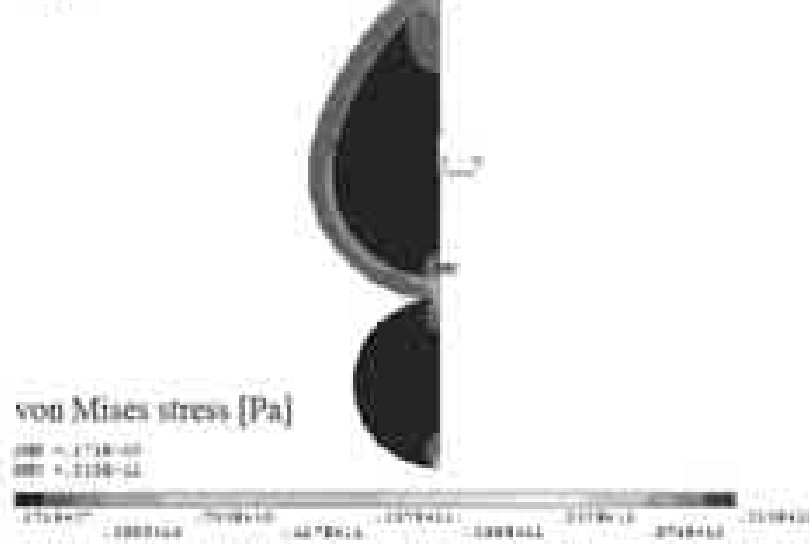

Fig. 9. von Mises stresses for angular position $\alpha=180^{\circ}$ for roller of tappet in respect to camshaft axis a) the first load case, b) the second load case 

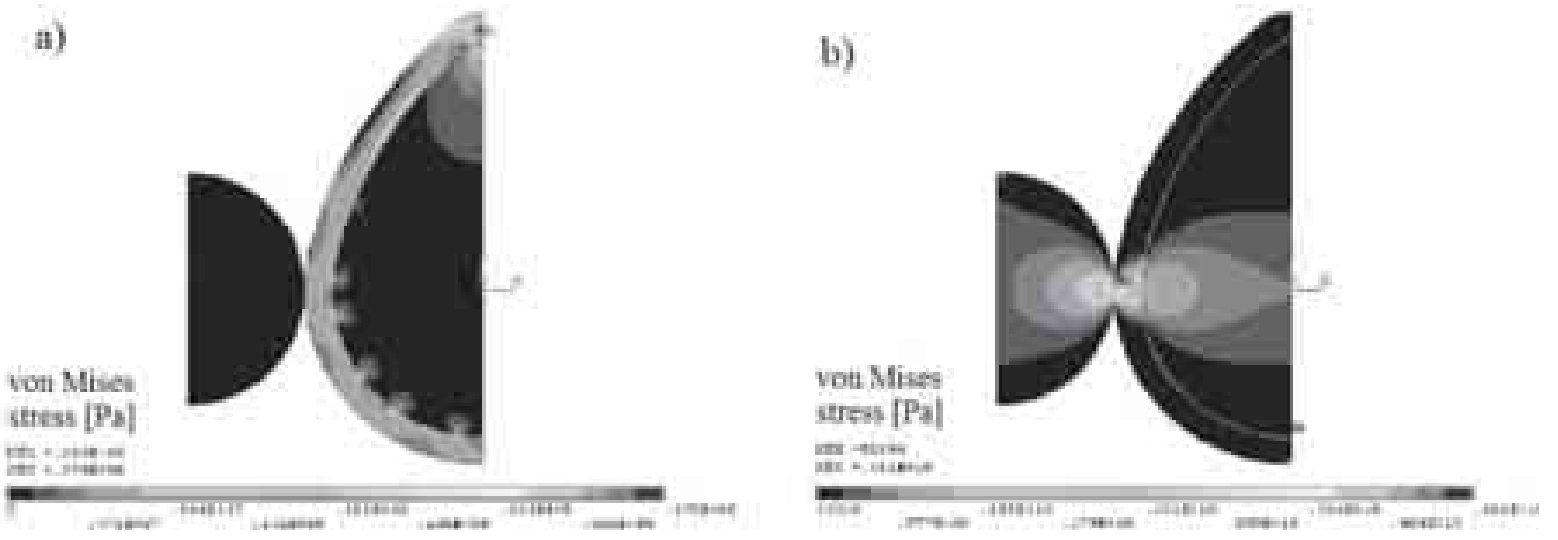

Fig. 10. von Mises stresses for angular position $\alpha=90^{\circ}$ for roller of tappet in respect to camshaft axis; a) the first load case, $b$ ) the second load case

\section{Conclusions}

1. Reducing the timing of moving masses, using roller lifters may also take place through the use of lightweight camshaft wrought of TiAl alloy, but having a steel cap placed in the manner of tight joint on the cam surface.

2. Exceeding of the material yield strength is controlled by the interference value between the cam and its cap and by the apex radius of the cam. Effect of contact stress is at least an order of magnitude smaller.

3. There is a need for very small apex radii between the cam and the cap. Selection of proper geometry of the cam will be easier after a proper modification of the program used for the synthesis and analysis of the cam mechanism, such that it has been possible to introduce any operating surface shape of the cam profile.

4. It is necessary to optimise the tight joint cam - cap.

\section{References}

[1] Matzke, W., Konstrukcja rozrządu silników szybkoobrotowych. WKiŁ, Warszawa 1974.

[2] Scania, Valve gear actuation, http://www.scania.co.uk/Trucks/technology/scania_modular_ combustion_concept/gear_actuation.asp, 13 April 2008.

[3] Scania, Technical Information 01, TI 01-03 0423 T/B pl. Edition 2, 2003.

[4] http://www.zss.lublin.pl/html/motor/11.8\%20Zadania\%20i\%20budowa\%20popychaczy.pdf

[5] http://www.lunatipower.com/Tech/Cams/FlatTappetOrRoller.aspx

[6] Ventiltriebkomponenten, Technik Schadensdiagnose, http://www.schaeffler.com/ remotemedien/media/_shared_media/library/automotiveaftermarket/catalogue/downloads_2/i na_vtk_de_de.pdf.

[7] Warda, B., Fatigue life prediction of the cam mechanism with roller follower, Tribologia, No. 6, pp. 223-233, 2007.

[8] Warda, B., Programy komputerowe do prognozowania trwałości zmęczeniowej węzłów tocznych o złożonej geometrii wspótpracujacych powierzchni, Mechanik, No. 11, pp. 966969, 2008.

[9] Warda, B., Wykorzystanie istniejacych teorii zmęczenia powierzchniowego do prognozowania trwałości złożonych węzłów tocznych, Zeszyty Naukowe PŁ, No. 1055, Z. 386, pp. 1-159, Łódź 2009.

[10] ANSYS v. 12.0 technical documentation. 